\title{
Saberes e práticas do ensino de Sociologia
}

\begin{abstract}
Anita Handfas'
Universidade Federal do Rio de Janeiro, Professora associada da Faculdade de Educação; Coordenadora do Laboratório de Ensino de Sociologia Florestan Fernandes
\end{abstract}

MAÇAIRA, J. P.; FRAGA, A. B. (org.). Saberes e práticas do ensino de sociologia. Rio de Janeiro: Autografia, 2018. $386 \mathrm{p}$.

0 livro em questão é resultado dos $4^{\circ}$ e $5^{\circ}$ Encontro Estadual de Ensino de Sociologia (Ensoc), ocorridos respectivamente em 2014 e 2016 e organizados pelo Laboratório de Ensino de Sociologia Florestan Fernandes (LabES), sediado na Faculdade de Educação da UFRJ. 0 Ensoc já é uma tradição no campo e tem reunido o que há de mais representativo e promissor na produção acadêmica sobre o ensino de sociologia na educação básica.

Trata-se de uma compilação de 12 artigos que versam sobre distintas dimensões da sociologia como disciplina escolar, que, em seu conjunto, oferecem um mapa bastante rico sobre o tema em pauta. A edição é cuidada, trazendo referências sobre os autores dos capítulos, já nos indicando uma autoria detentora de um olhar especializado sobre o tema. São 18 autores, em sua maioria professores de sociologia do ensino médio em escolas públicas do Rio de Janeiro. Além disso, o livro traz, também, em seu Prefácio e na Orelha, textos importantes de lleizi Fiorelli e Amaury Moraes, duas de nossas maiores referências no campo do ensino de sociologia.

Os organizadores - Julia Polessa Maçaira e Alexandre Barbosa Fraga - são professores e pesquisadores do tema, atuando em diversos espaços e projetos relacionados ao ensino e à formação do professor de sociologia. Ambos com formação em Ciências Sociais, Julia foi professora do ensino médio e atualmente é professora da Faculdade de Educação da UFRJ, onde coordena o Laboratório de Ensino de Sociologia Florestan Fernandes (LabES) e o Curso de Especialização em Ensino de Sociologia (CESPEB). Forma professores de sociologia e pesquisa o tema com o olhar voltado para os livros didáticos. Alexandre é professor de sociologia do ensino médio em uma escola pública do Rio de Janeiro e atualmente é professor substituto da Unirio. Sua atuação na pesquisa se divide entre estudos na área da sociologia do trabalho e do ensino de sociologia, em que tem pesquisado a história da disciplina e o currículo, tendo em vista a forma pela qual os conteúdos sociológicos se apresentam nas provas do ENEM.

Doutora em Educação pela Universidade Federal Fluminense; Mestre em Educação pela Universidade Federal do Rio de Janeiro; https://orcid.org/0000-0002-3804-7109; http://buscatextual.cnpq.br/buscatextual/visualizacv.do?id=K4730380Y7. 
0 livro está organizado em três grandes eixos, já consagrados nos círculos de debates sobre o tema: Eixo 1 - Novos olhares sobre a história do ensino de sociologia: para além dos marcos legais; Eixo 2 - Currículo prescrito e real: análises de documentos oficiais e de livros didáticos; e Eixo 3 - Práticas do ensino de sociologia: reflexões teórico-metodológicas no espaço escolar. Com efeito, é notável perceber a articulação desses grandes temas entre si, na medida em que os artigos conseguem trazer um olhar mais contextualizado da problemática tratada, fazendo com que sua compreensão ultrapasse a particularidade do tema e permita um olhar mais abrangente e articulado da história, do currículo e das práticas da sociologia como componente curricular na educação básica.

Nessa direção, é importante destacar alguns pontos comuns que permeiam os artigos.

No Eixo 1 do livro, composto por quatro artigos, a história da disciplina é narrada, como o próprio título diz, "para além dos marcos legais", o que já denota uma virada da produção acadêmica sobre o tema, uma vez que busca captar a sua trajetória em práticas sociais advindas do campo e de fora dele. Ou seja, aqui percebemos com maior clareza que a história da disciplina ultrapassa os meandros da lei e se move muito mais intensamente por meio de tensões dos agentes que em diferentes espaços disputam os sentidos da sociologia como disciplina escolar.

Assim, encontramos nesse primeiro Eixo dois artigos que fazem um balanço da produção acadêmica. No primeiro capítulo, a investigação se volta para os trabalhos apresentados nos Grupos de Trabalhos de quatro edições do Ensoc, e no seguinte são analisados artigos sobre o ensino de sociologia publicados em periódicos considerados de maior prestígio na comunidade acadêmica. Ainda nesse Eixo, encontramos um artigo que faz um retorno à década de 1930 para traçar a trajetória de dois intelectuais, autores de livros didáticos - Fernando de Azevedo e Amaral Fontoura -, e tentar compreender a dinâmica de constituição do campo sociológico e educacional a partir dos debates travados àquela época. Por fim, o último capítulo desse Eixo se volta para a cena política, acompanhando a tramitação de dois Projetos de Lei - n. 3.178/97 e n. 1.641/03 -, no Congresso Nacional para compreender as concepções das instituições políticas acerca da sociologia e sua relação com a cidadania.

Temos, enfim, nesse primeiro Eixo, artigos que buscam trazer, a partir de diferentes óticas, elementos importantes para a compreensão da história da sociologia como disciplina escolar. Um olhar atento perceberá que é preciso escapar das relações imediatas e, ao contrário, buscar nas conexões mais complexas e contraditórias a trajetória histórica de uma disciplina escolar.

Chegamos então ao Eixo 2 do livro, que reúne igualmente quatro capítulos trazendo reflexões interessantes sobre o currículo, entendido pelos autores desse Eixo 
como arena de disputas. São dois capítulos que analisam documentos curriculares e dois que têm especificamente o livro didático como objeto de análise. Aqui, mais uma vez, percebemos um avanço nas pesquisas sobre o ensino de sociologia, em particular naquelas que têm o currículo como ponto de partida. Desde que o livro didático ressurgiu mais recentemente respaldado por políticas públicas, as pesquisa sobre currículo de sociologia têm se ampliado, sendo adensadas por meio de reflexões teóricas a partir de autores da sociologia da educação, como é o caso de Basil Bernstein, também presente nesse livro.

No primeiro capítulo desse Eixo entramos nas disputas em torno do currículo de sociologia por meio da análise de quatro documentos curriculares - PCNEM, PCN+EM, OCEM e BNCC -, todos exemplares de como as diferenças dos discursos são sutis, justamente porque envoltas em tantas disputas, e que só podem ser identificadas por meio de uma leitura minuciosa dos documentos. Seguindo essa mesma perspectiva, o capítulo seguinte desse Eixo permanece na análise de documentos curriculares, porém dessa vez a partir de uma perspectiva comparada. Assim, temos a oportunidade de conhecer as especificidades do ensino de sociologia no sistema de ensino francês, e muito embora o artigo se detenha apenas nos programas de ensino deste País, os resultados da análise nos permitem refletir em uma perspectiva comparada sobre as semelhanças e diferenças entre os currículos de sociologia e de ciências sociais e econômicas do Brasil e da França, sobretudo no que diz respeito aos sentidos atribuídos à disciplina escolar. Os dois outros capítulos desse Eixo mergulham em um olhar mais focado para alguns aspectos do livro didático. Um desses capítulos analisa de maneira retrospectiva os conteúdos da antropologia presentes em nove livros didáticos existentes entre as décadas de 1920 e 1940, fornecendo pistas importantes para conhecer a maneira pela qual a antropologia se institucionalizou no Brasil. A esse respeito, interessante notar um aspecto que reforça a constatação do avanço nas pesquisas sobre o ensino de sociologia, que é a ocorrência de estudos que vêm apresentando cada vez mais elementos que demonstram como o conhecimento escolar sociológico foi determinante para a institucionalização das ciências sociais no Brasil. 0 último capítulo desse Eixo trata de uma dimensão muito presente nos livros didáticos brasileiros: as imagens. Particularmente nesse capítulo estão as indicações de filmes presentes nos livros didáticos de sociologia que passam por uma análise criteriosa para concluir que é preciso muito caminhar para se ter a imagem não como um apêndice no processo de ensino e aprendizagem, mas como uma ferramenta importante na mediação didática do conhecimento escolar.

0 terceiro Eixo reúne os quatro últimos capítulos. Esse Eixo parece completar o movimento referido anteriormente: a entrada dos sujeitos que convivem diariamente na escola com o ensino de sociologia fecha o livro nos dando a certeza de que a constituição de uma disciplina escolar se conforma por meio de processos que envolvem diferentes agentes em permanente disputa pelos seus significados. Nesse sentido, as práticas escolares evidenciadas nesse Eixo dão mais sentido aos artigos anteriores, na medida em que permitem 
conceber a história da disciplina e o currículo como processos, cuja dinâmica se constitui uma permanente articulação entre teoria e prática.

As vozes estudantis, com seus anseios e visões sobre a disciplina sociologia, aparecem de forma contundente nos dois primeiros capítulos desse Eixo, seja em meio as suas lutas quando do movimento de ocupação das escolas, seja por meio das relações que os alunos do ensino médio estabelecem com os saberes escolares da sociologia. Por outro lado, tal como tratado no capítulo seguinte desse Eixo, essas mesmas práticas escolares também podem ser identificadas em exames nacionais como o ENEM, cujo impacto sobre a rotina escolar é sentida pelos professores tanto do ponto de vista prático quanto no que concerne às mudanças que se anunciam no currículo, organizado agora por áreas de conhecimento. Esse Eixo e o livro se encerram de forma emblemática, pois, deliberadamente ou não, o último capítulo traz uma discussão tão sensível como necessária na conjuntura atual: a educação para os direitos humanos, tratada de forma qualificada, no sentido de refletir sobre a contribuição da disciplina sociologia no tratamento do tema.

0 conjunto de textos que compõe essa coletânea explicita o avanço do campo de pesquisas sobre o ensino de sociologia na educação básica, e talvez isso se mostre pela capacidade que o conjunto de artigos teve em saber articular o olhar sobre seus objetos de pesquisa a contextos mais amplos. Por tudo, Saberes e Práticas do Ensino de Sociologia oferece uma importante sistematização do debate sobre o ensino de sociologia na educação básica, suas potencialidades e limites. Só nos resta os votos de que outras coletâneas possam dar continuidade à publicização dos debates que vêm ocorrendo a cada dois anos no Ensoc.

Recebida em 8 de novembro de 2018

Aceita em 27 de novembro de 2018

Publicada em 25 de abril de 2019

Endereços para correspondência: Rua Silveira Martins, 129/807, 22221-000; Rio de Janeiro, Rio de Janeiro, Brasil; anitahandfas@gmail.com 